\title{
Preconcentration and Determination of Traces of Heavy Metals with Polymer Chelating Sorbents in the Analysis of Natural and Waste Water
}

\author{
Abdunnaser Mohamed Etorki ${ }^{1,}$, Ibrahim Salem Shaban ${ }^{2}$ \\ ${ }^{1}$ Department of Chemistry, University of Tripoli, Tripoli, Libya \\ ${ }^{2}$ Department of Environmental Science and Engineering, Libyan Academy, Tripoli, Libya
}

Email address:

a.etorki@ch.uot.edu.ly (A. M. Etorki)

\section{To cite this article:}

Abdunnaser Mohamed Etorki, Ibrahim Salem Shaban. Preconcentration and Determination of Traces of Heavy Metals with Polymer Chelating Sorbents in the Analysis of Natural and Waste Water. American Journal of Environmental Protection. Vol. 4, No. 2, 2015 , pp. $105-109$.

doi: 10.11648/j.ajep.20150402.16

\begin{abstract}
Monitoring the concentrations of heavy metals in natural and waste water at and below the level of their maximum permissible concentrations is an urgent environmental problem. Hence, new procedures for the preconcentration of heavy metals with their subsequent determination by different methods are required. Along with other sorbents, significant attention is attracted to polymer chelating sorbents, which provide individual or group extraction of trace elements, eliminate matrix effects, and provide high concentration factors. The effect of the various parameters such as electrochemically and chemically synthesis methods, physical oxidation state of the polymer, polymer thickness, solution $\mathrm{pH}$ and metal ion concentration on the adsorption, kinetics and efficiency were investigated. The results showed a vary broad concentration range of the heavy metals from ( 0.05 to $10 \mathrm{mg} / \mathrm{L}$ ) can be adsorbed on different kinds of polymers at different $\mathrm{pH}$ values and different efficiently. The adsorption capacity of the polymer to different concentrations of heavy metals was evaluated as the milligram of metal ions by one gram of various forms of the polymer. The DC conductivity measurements were also employed on the solid polymer before and after adsorption of metal ions. The experimental adsorption date was fitted to different mathematical isotherms to estimate the binding constant of heavy metals with the polymer in both single and mixed ion solutions. The method provides the extraction of analytes from natural water of complex composition containing high concentrations of alkali, alkaline-earth and other elements and is characterized by rapidly, selectivity, low detection limits, and a high reproducibility of the results. The relative standard deviation is $2-4 \%$. The technique was test with real waste water samples.
\end{abstract}

Keywords: Polymers Sorbents, Heavy Metals, Preconcentration, Adsorption Isotherms, Mixed Ion Solutions, Selectivity

\section{Introduction}

The selective adsorption and removal of metal ions in aqueous environmental samples prior to determination have received increasing importance in environmental evaluation and protection in recent years. Adsorption is the concentration of a substance at the surface or interface [1]. The adsorption at a surface or interface is largely as a result of binding forces between atom, molecules, and ions of the adsorbate on the surface [2]. The commercial adsorbents used today for the removal of heavy metals from solutions include a variety of clays, activated carbon, gels, alumina, silica, zeolites, and other resinous material. Spectrometry techniques, including atomic absorption spectrometry (AAS) and inductively coupled plasma optical emission spectrometry (ICP-OES) as well as inductively coupled plasma mass spectrometry (ICP-MS) are the most commonly used analytical methods for trace metals determination. In practice for complex matrices, however, the accurate determination of trace metals is frequently very difficult due to the presence of interfering effects, comprising spectroscopic and non-spectroscopic interferences. Moreover, in some cases, analyte concentration might be to low to be analysed directly. For the purpose of separation of metal ions either for purification or enrichment, various kinds of different sorbents have been developed. This has been the subject of numerous papers and review articles related to synthesis,

Characterization and metal ion uptake studies.

Intrinsic conducting polymers with conjugated double bonds have been attracted much attention as advances 
materials due to their multifunctional properties and potential applications. They can be easily synthesized in both aqueous and organic solvents, chemically and electrochemically. Recently, the use of aniline, pyrrole and phenyl-based polymers as sorbents in solid phase extraction technique has been demonstrated [3-5]. Polypyrrole was applied for extraction of phenol and chlorophenols [6], while applicability of polyaniline was investigated for the preconcentration and speciation of mercury [7] as well as for determination of $\mathrm{Cd}$, $\mathrm{Cu}, \mathrm{Pb}$ and $\mathrm{Sb}$ in potassium iodide medium in biological matrices [8]. The microparticles of sulfodiphenylamine and diaminonaphtalene copolymers were tested for adsorption of $\operatorname{Ag}(\mathrm{I})$ [9], while poly(m-phenyldiamine) microparticles were used for recovery of lead ions [10].

Due to be rapidly applications of polymer chelating ligands in environmental analytical chemistry, the present study is undertaken with the following specific objectives:

1. to examine the performance and effectiveness of electrochemically and chemically synthesized poly-(2-isopropyl aniline) in removal of $\mathrm{Cd}(\mathrm{II}), \mathrm{Pb}(\mathrm{II})$, and $\mathrm{Zn}(\mathrm{II})$ ions by adsorption from waste water.

2. to determine the effect of initial metal concentration, $\mathrm{pH}$ and temperature on the adsorption capacity of the electrochemically and chemically synthesized poly-(2-isopropyl aniline).

3. to study the applicability of the Langmuir, Freundlich and Frumkin isotherms;

4. to provide additional information on the adsorption of the relevant heavy metal cations by the electrochemically and chemically synthesize poly-(2-isopropyl aniline); and

5. to understand the mechanism of adsorption of the relevant metal cations by the electrochemically and chemically synthesize poly-(2-isopropyl aniline) based on parameters such as adsorbent capacity, free energy change, enthalpy change and entropy change.

\section{Experimental}

\subsection{Material and Methods}

Deionized doubly distilled water was used to prepare all solutions. Stock solutions of metal ions were prepared from their nitrate salts $\mathrm{Cd}\left(\mathrm{NO}_{3}\right)_{2} \quad .4 \mathrm{H}_{2} \mathrm{O}, \quad \mathrm{Zn}\left(\mathrm{NO}_{3}\right)_{2} \quad .6 \mathrm{H}_{2} \mathrm{O}$ and $\mathrm{Pb}\left(\mathrm{NO}_{3}\right)_{2}$ (Fluka). All metal working standards were prepared by dissolving appropriate amount of metal salt into deionized water. Nitric acid and sodium hydroxide were both analytical reagents grade (Merck). 2-isopropyl aniline was used without further purification and supplied from (Aldrich).The solution of the polymer was prepared in deionized doubly distilled water.

\subsection{Preparation of the Polymer (Adsorbent)}

poly-(2-isopropyl aniline) with different molecular weights: $90,000,120,000$ and 180,000, were synthesised by the oxidative polymerization of 2-isopropyl aniline in aqueous $\mathrm{HCl}$ solution using potassium dichromate as the oxidant, 11.5 mmol of monomer and $2 \mathrm{mmol} \mathrm{K}_{2} \mathrm{Cr}_{2} \mathrm{O}_{7}$ were dissolved in 10 $\mathrm{ml}$ of $1.5 \mathrm{M} \mathrm{HCl}$ solution, separately. The $\mathrm{K}_{2} \mathrm{Cr}_{2} \mathrm{O}_{7}$ solution was added drop wise to the stirred monomer solution at room temperature. The black precipitate was filtered, after a $1 \mathrm{~h}$ reaction period, and then washed with $1.0 \mathrm{M} \mathrm{HCl}$ solution until the filtrate was clear. The polymer was dried under vacuum at $80^{\circ} \mathrm{C}$ for $48 \mathrm{~h}$.

\subsection{Apparatus}

An atomic emission spectrometer (ICP-OES, Perkin Elemer, Optima 5300, USA ) with a wipro Dell computer was used. A WTW digital $\mathrm{pH} / \mathrm{mV}$ meter (model $\mathrm{pH}-340-\mathrm{A} / \mathrm{SET} 2$ ) with a combination glass electrode (WTW D82362 Weiheim) was used for all $\mathrm{pH}$ measurements. A Damon model centrifuge equipped to timer and speed control was employed for centrifuging of samples. The DC conductivity measurements were carried out on compressed pellets by using a tow probe technique at room temperature.

\subsection{Sampling}

The tannery wastewater samples were collected in pre-washed (with detergent, deionized doubly distilled water, dilute $\mathrm{HNO}_{3}$ and deionized doubly distilled water respectively) polyethylene bottles from Abe Kammash Industrial Region (Zwara)-Libya. The samples were filtered through Millipore cellulose nitrate membrane of pore size $0.45 \mu \mathrm{M}$. The samples were stored in 1 litre polyethylene bottles and acidified to $1 \%$ with nitric acid and were subsequently stored at $4^{\circ} \mathrm{C}$ in a refrigerator.

\subsection{Adsorption and Analytical Procedure}

The adsorption of heavy metals on poly-(2-isopropyl aniline) was carried out using the batch method. Batch adsorption experiments were conducted using $100 \mathrm{mg}$ of adsorbent with $20 \mathrm{~mL}$ of solutions containing heavy metal ions of desired concentrations at different temperature $25^{\circ} \mathrm{C}$ and $\mathrm{pH}$ values (3.0, 5.0, 6.0 and 7.0) in $50 \mathrm{~mL}$ glass stoppered flasks. The $\mathrm{pH}$ of solutions was adjusted by using dilute $\mathrm{NaOH}$ or $\mathrm{HCl}$ solutions before adsorption analysis. The flasks were shaken in a temperature-controlled water bath for $30 \mathrm{~min}$ with the mixing rate of $350 \mathrm{rpm}$ and the solutions containing heavy metals were filtered through Whatman filter paper (No. 42) after the contact time of $30 \mathrm{~min}$. The exact concentration of metal ions and filterable metal concentrations were determined by (ICP-OES).

The maximum loading capacity of the polymer was determined by applying the above procedure with higher concentration of analyte. To obtain a completely metal-free polymer, the procedure was repeated four times. To regenerate the polymer, i.e., to obtain a metal-free polymer again in order to use further in other experiments, after the full procedure was completed, a $3 \mathrm{ml}$ of $4 \mathrm{~mol} \mathrm{~L}^{-1} \mathrm{HNO}_{3}$ was added on to the polymer and analyte elements which remained from a previous procedures. The polymer was used in other experiments again.

\subsection{Constants}

The percent adsorption $(\%)$ and distribution ratio $\left(K_{\mathrm{d}}\right)$ were 
calculated using the equations

$$
\% \text { Adsorption }=\left[\left(C_{\mathrm{i}}-C_{\mathrm{f}}\right) / \mathrm{C}_{\mathrm{i}}\right]^{*} 100
$$

where $C_{\mathrm{i}}$ and $C_{\mathrm{f}}$ are the concentrations of the metal ion in initial and final solutions, respectively, and

$K_{\mathrm{d}}=$ (amount of metal ion in adsorbent)/(amount of metal ion

$$
\text { in solution }) \times V / m(\mathrm{~mL} / \mathrm{g}) \text {, }
$$

where $V$ is the volume of the solution $(\mathrm{mL})$ and $m$ is the weight of the adsorbent (g) [11].

\section{Results and Discussion}

\subsection{Effect of pH on Recoveries of Analytes}

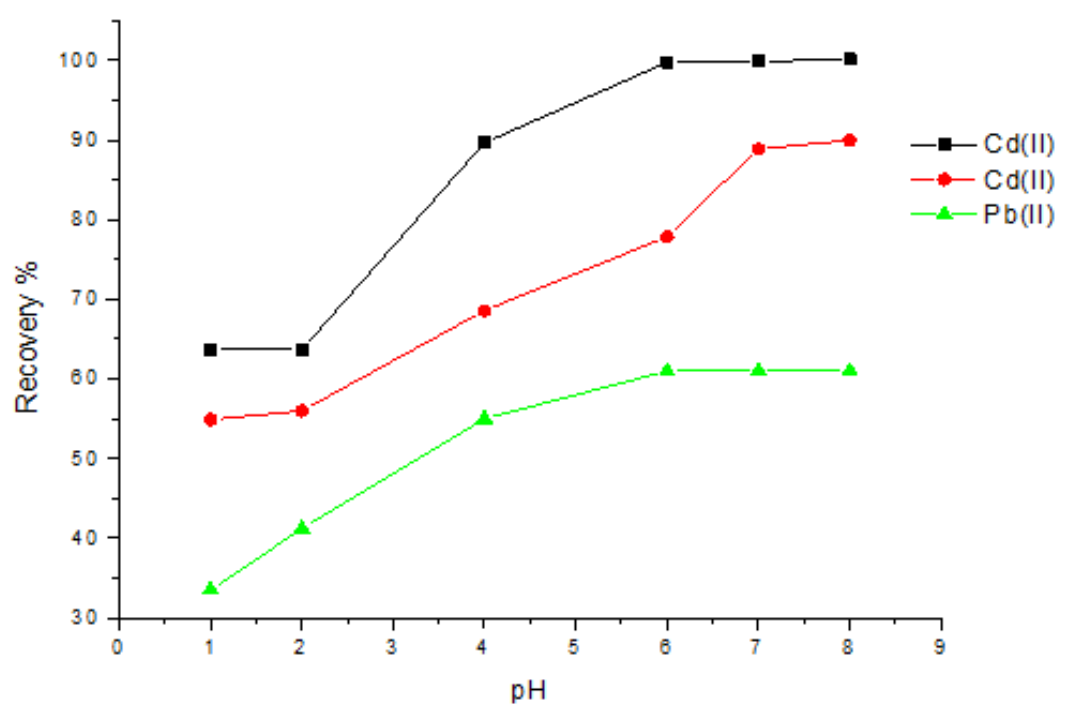

Figure 1. Effect of $p H$ on removal of cadmium.

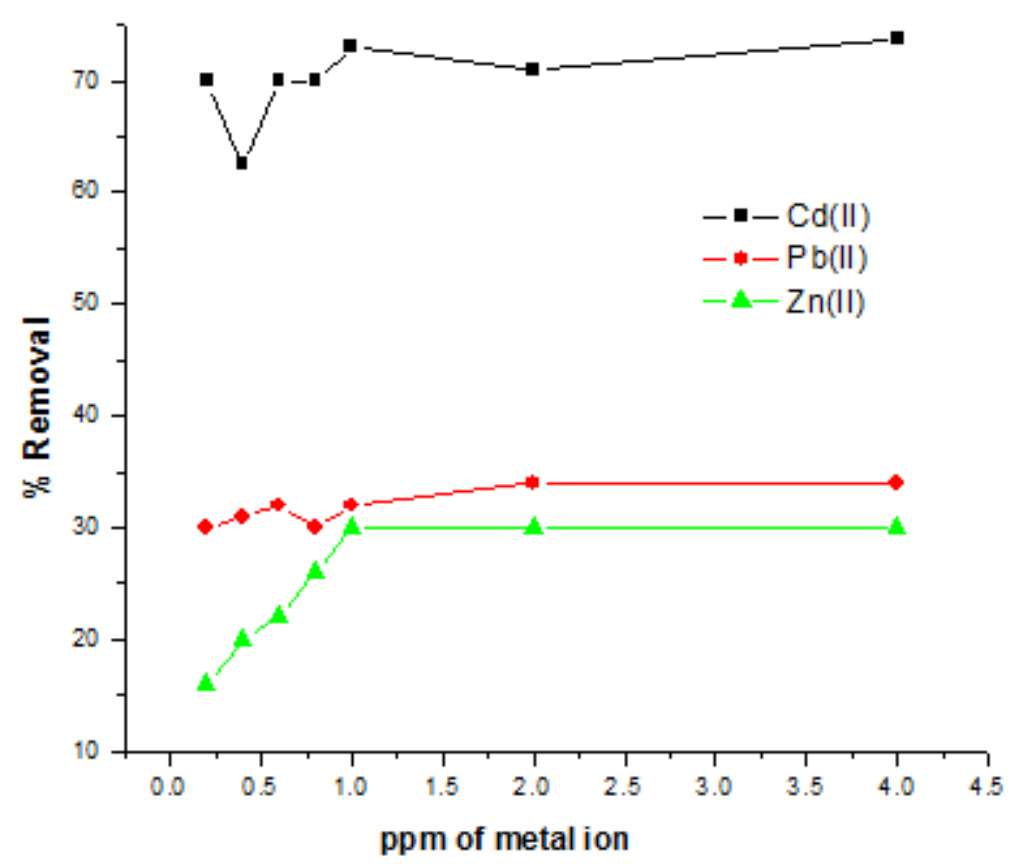

Figure 2. Effect of initial concentration on removal of cadmium. 


\subsection{Adsorption Isotherm}

The experimental adsorption isotherms were fitted to mathematical Langmuir and Freundlich isotherms models. For the Langmuir model, the following equation was used:

$$
\mathrm{q}_{\mathrm{eq}}=\mathrm{q}_{\mathrm{m}} \mathrm{C}_{\mathrm{eq}}\left(\mathrm{K}_{\mathrm{d}}+\mathrm{C}_{\mathrm{eq}}\right)
$$

where $\mathrm{q}_{\mathrm{eq}}$ and $\mathrm{C}_{\mathrm{eq}}$ correspond to the milligrams of $\mathrm{Hg}$ adsorbed per one gram of the polymer and the residual $\mathrm{Hg}$ concentration in the solution when in equilibrium and $\mathrm{K}_{\mathrm{d}}$ and $\mathrm{q}_{\mathrm{m}}$ are Langmuir constant and maximum capacity of adsorption for this model. Freundlich isotherm constants were calculated with the equation:

$$
\operatorname{lnq} \mathrm{qq}_{\mathrm{eq}}=\mathrm{n} \ln \mathrm{C}_{\mathrm{eq}}+\ln \mathrm{K}_{\mathrm{F}}
$$

where $\mathrm{K}_{\mathrm{F}}$ and $\mathrm{n}$ are the Freundlich constants characteristic of the polymer system. The Langmuir model is valid for modelling monolayer adsorption onto a homogenous surface with constant adsorption energy; the Freundlich equation posits a heterogeneous surface and considers that molecules attached to a surface site will have an effect on the neighbouring sites. The adsorption data from the different initial concentrations of $\mathrm{Cd}(\mathrm{II}), \mathrm{Pb}(\mathrm{II})$ and $\mathrm{Zn}(\mathrm{II})$ were analyzed in terms of both Langmuir and Freundlich equations at $\mathrm{pH}=6.4$ and $25^{\circ} \mathrm{C}$, and the values obtained for the respective constants are shown in Table 1 .

Table 1. Langmuir and Freundlich constants for Cd(II) Pb(II) and Zn(II) / poly-(2-isopropyl aniline).

\begin{tabular}{lllll}
\hline Metals & $\mathbf{q}_{\mathbf{m}}\left(\mathbf{m g ~ g}^{\mathbf{- 1}}\right)$ & $\mathbf{K}_{\mathbf{d}}\left(\mathbf{L} \mathbf{~ m g}^{-\mathbf{1}}\right)$ & $\mathbf{1} / \mathbf{n}\left(\mathbf{L ~ g}^{-\mathbf{1}}\right)$ & $\mathbf{K}_{\mathbf{F}}\left(\mathbf{m g ~ g}^{-\mathbf{1}}\right)$ \\
\hline $\mathrm{Cd}(\mathrm{II})$ & 77.2 & 0.412 & 0.243 & 10.04 \\
$\mathrm{~Pb}(\mathrm{II})$ & 13.3 & 0.180 & 0.122 & 4.22 \\
$\mathrm{Zn}(\mathrm{II})$ & 11.7 & 0.164 & 0.101 & 3.58 \\
\hline
\end{tabular}

The Langmuir isotherm equation $\left(r^{2}=0.9973\right)$ seemed to describe better the adsorption process of $\mathrm{Cd}(\mathrm{II})$ by poly-(2-isopropyl aniline) than the Freundlich isotherm $\left(r^{2}=0.9910\right)$. the determination coefficients $\left(r^{2}\right)$, used to describe the fitness between the experimental and theoretical models, were high for both equations (Figure 3), and the applicability of both Langmuir and Freundlich isotherms implied that both monolayer adsorption and heterogeneous surface conditions exist under the experimental conditions used here, with the latter process prevailing. According to reference [9], if $0.1<1 / \mathrm{n}<1.0$, the adsorption of an adsorbent on the polymer is favourable. In this study $1 / \mathrm{n}$ was 0.33 , indicating that the polymer can be used effectively for removal of Cd(II) from aqueous solutions.

\subsection{Conductivity Measurements}

The DC conductivity measurements were also employed on the solid polymer before and after adsorption of cadmium ions. The results are shown in table 2 . The DC conductivity of the poly(2-isopropyl aniline) alone was $0.9 \times 10^{-6} \mathrm{ohm}^{-1} \mathrm{~cm}^{-1}$ The results shown that the DC conductivity increases with increase concentration of cadmium ions in solution after the polymer adsorbed cadmium ions from single metal ion solutions.
Table 2. DC conductivities for poly(2-isopropyl aniline) after adsorbed cadmium ions from solution.

\begin{tabular}{ll}
\hline Ppm of Cd(II) & DC Conductivity $\mathbf{x} \mathbf{1 0}^{-\mathbf{6}} \mathbf{O h m}^{-\mathbf{1}} \mathbf{c m}^{-\mathbf{1}}$ \\
\hline 0.2 & 19.2 \\
0.4 & 19.4 \\
0.6 & 40.0 \\
0.8 & 37.5 \\
1.2 & 57.5 \\
1.5 & 69.6 \\
2.0 & 79.5 \\
2.5 & 87.3 \\
3.0 & 87.4 \\
3.5 & 99.3 \\
4.0 & 97.4 \\
4.5 & 97.2 \\
\hline
\end{tabular}

\subsection{Removal of Cd(II) Ions from Wastewater Samples}
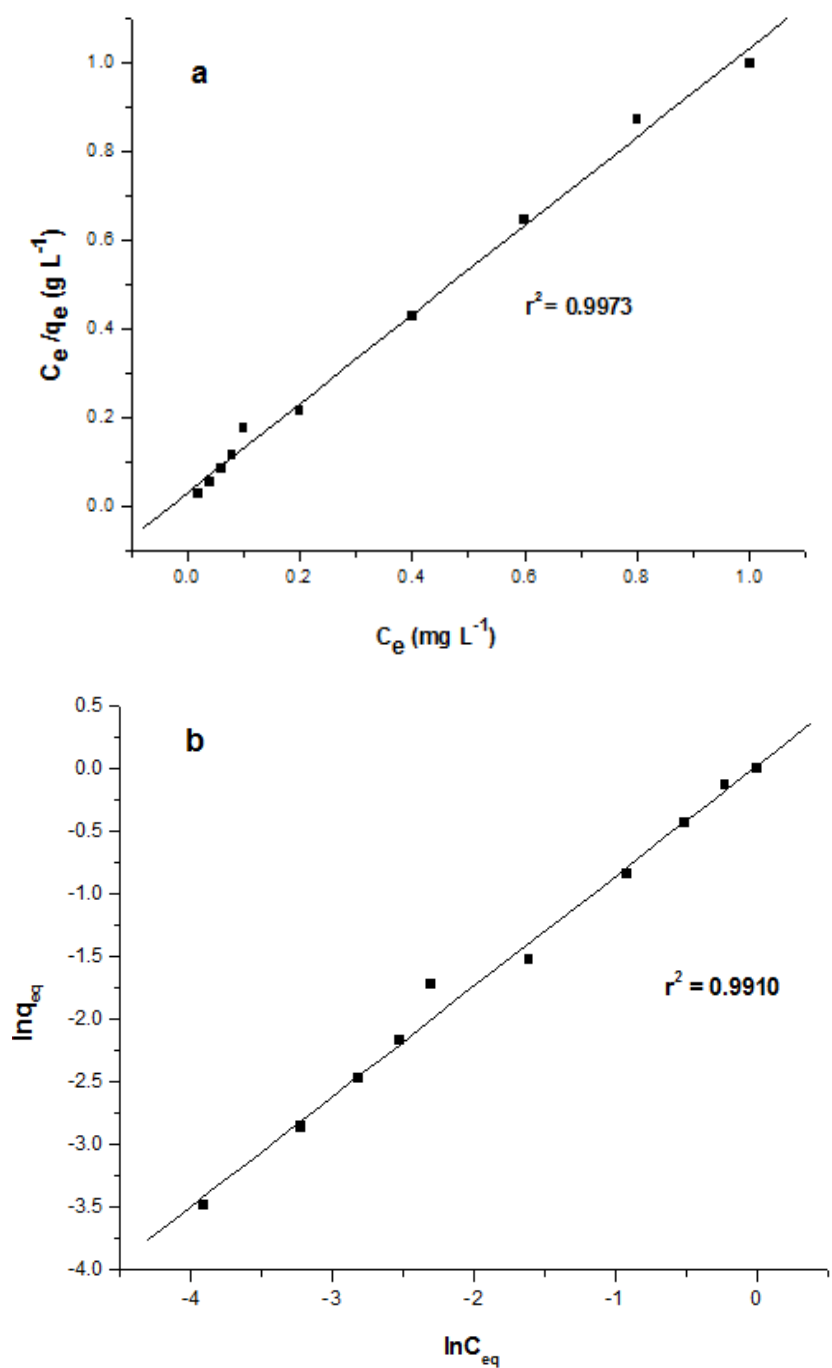

Figure 3. Cd(II) adsorption isotherm based on the (a) Langmuir and (b) Freundlich models.

The wastewater samples were firstly characterised by ASTM and ISO standard methods. The wastewater samples were found to contain 0.1-5.0 and 0.05-2.0 $\mathrm{mg} \mathrm{l}^{-1}$ of cadmium (II), respectively. Six samples were digested with nitric acid, 
followed by $\mathrm{pH}$ adjustment and treatment with the poly-(2-isopropyl aniline) under the optimized conditions described above .Assay of mercury in the final effluents indicates $97.2-99.5 \%$ removal of the original concentrations. The mean standard deviation is $\pm 1.3 \%$. The adsorption capacities were $70.5 \mathrm{mg} / \mathrm{g}$ for for $\mathrm{Cd}(\mathrm{II}), 15.3 \mathrm{mg} / \mathrm{g}$ for $\mathrm{Pb}(\mathrm{II})$ and $12.4 \mathrm{mg} / \mathrm{g}$ for $\mathrm{Zn}(\mathrm{II})$.

\section{Conclusions}

Poly-(2-isopropyl aniline) could be successfully applied for the preconcentration and separation of cadmium, lead and zinc ions from aqueous solutions prior to their analysis by ICP-OES. The suggested method has been applied to different wastewater samples with the satisfactory precision and accuracy.

\section{References}

[1] C. Kadirvelu, C. Faur-Brasquet, P. Le Cloirec, "Removal of $\mathrm{Cu}(\mathrm{II}), \mathrm{Pb}$ (II) and $\mathrm{Ni}$ (II) by Adsorption onto activated carbon cloths" Langmuir 16, pp. 8404-8409 (2000)

[2] D. Sedlak, J.T. Phinney, W.W. Bedsworth, "Strongly complexed $\mathrm{Cu}$ and $\mathrm{Ni}$ in wastewater effluents and surface runoff," Environ. Sci. Technol, vol. 31, pp. . 3010-3016, 1997.

[3] R.A. Issac, L. Gil, A.N. Cooperman, K. Hulme, B. Eddy, M. Ruiz, K. Jacobson, C. Larson, O.C. Pancorbo, "Corrosion in drinking water distribution systems: A major contribution of copper and lead to wastewaters and effluents," Environ. Sci. Technol, vol.31, pp. 3198-3203, 1997.
[4] M.A. Schneegurt, J.C. Jain, J.A. Menicucci Jr., S.A. Brown, K.M. Kemner, D.F. Garofalo, M.R. Qualick, C.R. Neal, C.F. Kulpa Jr., "Biomass by-products for The remediation of wastewaters contaminated with toxic metals," Environ. Sci.Technol,. vol 35, pp.3786-3791, 2001.

[5] C.F.Poole, New trends in solid-phase extraction," Trends in Analytical Chemistry," vol.22, pp.362-373, 2003.

[6] R. Rao, T.R.Kala and S.Danial, "Metal ion-imprinted polymers novel materials for selective recognition of inorganics," Analytical Chim Acta, vol 578, pp.105- 116, 2006.

[7] A. Muck and A. Svatos.,"Chemical modification of polymeric microchip devices," Talanta, vol 74, pp. 333-341, 2007.

[8] A.C.Sahayamg,"Determination of $\mathrm{Cd}, \mathrm{Cu}, \mathrm{Pb}$, and $\mathrm{Sb}$ in environmental samples by ICP-AES using polyanline for separation,"Fresenius J Anal Chem, vol 362, pp.285-288,1998.

[9] J.R.Fischer, D.Pang and T.S.Beatty, "Silica-polyamine composite materials for heavy metal ion removal, recovery and recycling. II. Metal ion separations from mine wastewater and soft metal ion extraction efficiency," Separation Science and Technology, vol 34, pp.3125-3137, 1999.

[10] W.A.Ibrahim, L.I.AbdoAli, A.Sulaiman, M.M.Sanagi, H.Y.Abdoul-Enein, "Application of solid phase extraction for trace elements in environmental and biological samples," Critical Reviews in analytical Chemistry, vol 44, pp. 233-254, 2014.

[11] M.A.Oskooie,M.M.H.Heravi, "Preparation and application of poly(2-aminothiophenol)MWCNTs nanocomposites for adsorption and separation of cadmium and lead ions via solid phase extraction", J. Hazard. Mater, vol 203-204, pp.93-100, 2012. 